\title{
Application of ultrasonic clamp-on flow meters for in situ tests of billing meters in district heating systems
}

\author{
Bernt Svensson *, Jerker Delsing \\ Luleå University of Technology, Industrial Electronics, S-971 87 Luleå, Sweden
}

Received 21 January 1997; received in revised form 9 July 1997; accepted 28 January 1998

\begin{abstract}
Three methods of using ultrasonic flow meters for the purpose of testing small- and medium-sized billing flow meters in district heating subscriber stations in situ were investigated. Four subscriber stations, six billing flow meters, and three ultrasonic clampon meters were part of the investigation. The obtained results show that clamp-on meters have measurement accuracy problems on the ordinary steel piping in the subscriber stations. When using well defined pipes mounted in series with the billing flow meters the results are clearly better; provided that the flow rates exceed a Reynolds number of approximately 10000 . In this flow region, billing flow meter deviations $> \pm 5 \%$ can be detected. A flow rate below this Reynolds number renders the method less reliable. The useful flow range is extended when using calibration data from the clamp-on meter to correct the measured data, making it possible to determine deviations $> \pm 10 \%$ in flow rates below a Reynolds number of 10000 . The investigation also showed that not all clamp-on meters are suited for this type of in situ test. (C) 1998 Elsevier Science Ltd. All rights reserved.
\end{abstract}

Keywords: Flow meters; Ultrasonic; Reynolds number; District heating systems

\section{Introduction}

Fair cost distribution and energy meter reliability in district heating systems, in general calls for improved measurement accuracy. The energy meter comprises a flow meter, two temperature sensors, and an integration unit. The part of the energy meter that most often causes problems is the flow meter. Flow meter problems have a number of causes such as static or dynamic flow disturbances, fouling, ageing and wearing. These disturbances can cause large measuring errors of often unknown magnitude and duration. This calls for test methods usable in the environment of district heating.

Normally, exchange programs are used to cope with flow meter problems. Errors caused by the flow meter itself can often be detected afterwards when removed from the line during meter reverification, however these tests will not quantify the errors due to the installation. This lack of available and appropriate tests shows the need for a test method that can be used in situ at the

* Corresponding author. Tel.: 004646 2224636; Fax: 004646 2224717. subscriber station for the detection of installation errors and also for obtaining a survey of the magnitude of the errors caused by the installations.

One well known in situ method for flow measurement in closed conduits is the addition of a diluted tracer solution [1-4]. In district heating subscriber stations, radioactive tracers have been used to calibrate large flow meters $\left(>400 \mathrm{~m}^{3} / \mathrm{h}\right)$. In tests, uncertainties of around $\pm 1 \%$ are obtained [5]. However, this method requires access to the fluid for tracer injection and is expensive.

Cross-correlation flow meters require some detectable variable present in the fluid. In practice, detection of the fluctuations has shown to be unreliable and difficult $[6,7]$.

Insertion meters can be used in most flow measurement applications and utilize most of the traditional flow sensing technologies (i.e. turbine, vortex, magnetic, dP) [1]. An insertion flow meter operates by inferring the total flow rate in a pipe from measurements of the velocity at specific locations within the pipe, requiring good knowledge of the flow profile. However, tests have shown significantly overstated velocities for low flow rates [8].

For the purpose of taking in situ measurement in dis- 
trict heating subscriber stations, where pipe diameters normally range between 25 and $100 \mathrm{~mm}$ and the relation between the maximum design flow rates and the real minimum flow rates not seldom exceeds 200:1, the above mentioned methods are either too expensive or clearly impractical. For that reason ultrasonic clamp-on flow meters have the potential to become the in situ method of choice for testing small- and medium-sized flow meters. Despite its potential, ultrasonic clamp-on meters have several problems. Some of these are mentioned below.

Clamp-on meters are sensitive to pipe quality. One parameter to consider is the pipe wall thickness. If the ratio between pipe diameter $(D)$ and wall thickness $(t)$ becomes too small, a relatively large part of the ultrasonic pulses will travel around the pipe wall instead of passing through the fluid. This can cause non-linearity and zero drift and has been investigated, among others, by Cairney [9]. He found that the errors increased markedly when $D / t$ was around 10:1 and increased to nearly $10 \%$ when $D / t$ ratio decreased down to five.

It is also very important to know the inner diameter of the pipe. A small error in measuring the pipe diameter can result in rather large errors. If, for example, an error of one millimeter in determining the diameter of a oneinch pipe is made, this will correspond to an error of around $8 \%$ for the total flow rate. Bruner [10] has tested the removal and reinstallation of the ultrasonic transducers on the same pipe to isolate the act of reapplying a clamp as a source of uncertainty. Bruner found that this could give an estimated reading uncertainty of almost \pm $5 \%$, but the tests were made with only one flow measuring system. Errors derived from the reclamping of the meter may occur due to misalignment of the transducers or poor acoustic coupling between the transducers and the pipes [11].

The aim of the present investigation is to test if it is possible to use ultrasonic clamp-on meters to test the billing meters in district heating systems. In a laboratory environment the use of ultrasonic clamp-on meters are assumed to be feasible. For the purpose of using ultrasonic clamp-on meters in a district heating environment, three different ways to apply ultrasonic clamp-on meters in real operation situations are investigated. These are:

(A) Application of clamp-on meter on ordinary steel piping.

(B) Introduction of an internally polished, high quality, thin walled, stainless steel pipe installed in series with the billing flow meter.

(C) Use of calibration data to extend the usable flow range for the clamp-on meter.

Tests have been performed over a period of 18 month using three ultrasonic clamp-on meters of different brands at four different locations, called metering sites. The clamp-on meters tested are commercially available and their flow ranges are chosen to fit the billing meters design flow rates. The investigation does not include pipeline ageing effects.

\section{Method}

To investigate the feasibility of ultrasonic clamp-on meters as an in situ test tool for flow meters, three different ways to apply clamp-on meters have been tested. In all the tests the clamp-on meter is installed in series with the process flow meter to be checked.

\section{1. (A) Application of clamp-on meter on ordinary steel piping}

The first in situ method is to fasten the clamp-on meters on the ordinary steel piping used in the district heating subscriber stations. The measurements were taken on steel pipes according to Swedish standard 1886, very similar to DIN 1626 [12].

\section{2. (B) Introduction of an internally polished, high quality, thin walled, stainless steel pipe installed in series with the billing flow meter}

One disadvantage of clamp-on meters is that the accuracy of measurement depends on wall thickness, pipe material, and surface roughness. This means that pipe data must be known accurately. In this test, therefore a thin walled, high quality, polished on the inside stainless steel pipe, is introduced in series with the billing flow meter. These well defined pipes are equipped with special locations (i.e. 'mounting heels') to ensure repeatable mounting of the clamp-on meter. An example of the installation of a clamp-on meter in one of the metering sites is shown in Fig. 1.

\section{3. (C) Use of calibration data to extend the usable flow range for the clamp-on meter}

Two of the used clamp-on flow meters have been calibrated together with the internally polished thin walled stainless steel pipes used in (B). These calibration data are used to extend the useful flow range for the clampon meters.

For the three ways of applying the clamp-on meters described above, the deviation between the ultrasonic clamp-on meter and the installed flow meter has been taken as an indicator of proper operation of the billing meter. Further, analysis of the data is used to determine if the clamp-on meters are capable of performing to the required accuracy. 

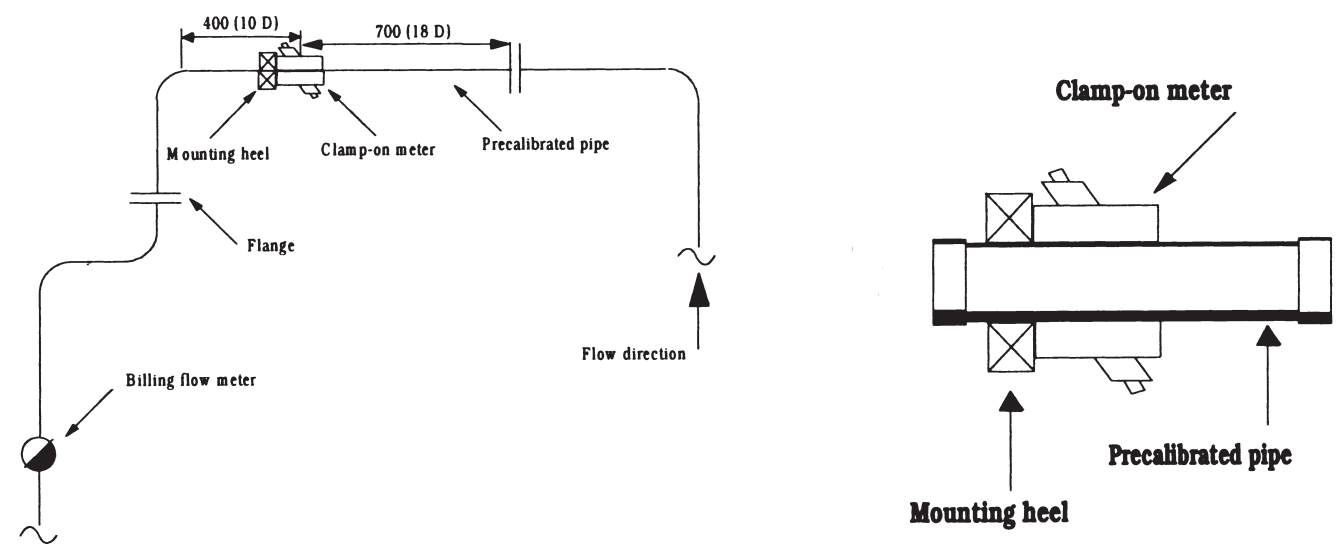

Fig. 1. Outline of installation of clamp-on meter in metering site 3 (left) and enlargement of the heels used to secure equal good mounting position of the clamp-on meter (right).

\subsection{Experimental}

To test the proposed in situ methods, four subscriber stations in two different district heating networks were made available by the Energy Utilities in the cities of Malmoe and Lund in Sweden. Measurements have been taken once a month over a period of approximately one and a half year. The data presented are a comparison between the billing meter and the clamp-on meter over a period of one hour. Three different brands of ultrasonic clamp-on meters and three types of billing flow meters have been used for this tests. Data for the four subscriber stations are shown in Table 1. The ultrasonic clamp-on meters used in the investigation are all flowmeters using the transit-time method [13]. Data for the clamp-on meters are shown in Table 2.

\subsection{1. $\operatorname{Method}(A)$}

Measurements were taken on two metering sites using clamp-on meters ' $\mathrm{Y}$ ' and ' $\mathrm{Z}$ '. At each site, measurements were taken with one clamp-on meter mounted on the ordinary pipes in the subscriber station and one clamp-on meter mounted on a calibrated pipe as a reference measurement. Both clamp-on meters were compared to the billing flow meter in the site.

\subsubsection{Method (B)}

Measurements were taken on four metering sites using clamp-on meters ' $\mathrm{X}$ ' and ' $\mathrm{Y}$ '. At each site, measurements were made with one clamp-on meters at a time mounted on the well defined pipes in the subscriber stations. In front of the clamp-on meters there are at least 14 and up to over 40 pipe diameters of straight pipe length (Table 1).

\subsubsection{Method (C)}

Clamp-on meter ' $\mathrm{X}$ ' has been calibrated together with all pipes before they were installed in the subscriber stations. Clamp-on meter ' $Y$ ' was not available until after the mounting of the pipes was made. Therefore this meter has been calibrated with a fifth pipe, made in the same manner as the other four installed pipes. The wall thickness is $2.1 \mathrm{~mm}$ for all five pipes. The outer diameters of the four installed pipes are shown in Table 1 and the fifth pipe has a outer diameter of $60.2 \mathrm{~mm}$. Calibration data are presented in Fig. 2. Each calibration consists of three series of measurements, with the clampon meter being reclamped between the series. The water temperature was $40-45^{\circ} \mathrm{C}$, which is the normal return temperature in the subscriber stations. The test rig has a total uncertainty of $<0.3 \%$.

Table 1

Pipe and flow meter data from the four subscriber stations

\begin{tabular}{|c|c|c|c|c|c|c|}
\hline \multirow[t]{2}{*}{ Site } & \multicolumn{3}{|c|}{ Pipe data } & \multicolumn{3}{|c|}{ Billing flow meter } \\
\hline & $\mathrm{OD}(\mathrm{mm})$ & $\begin{array}{l}\text { Reynolds number } \\
\text { at } 1 \mathrm{~m}^{3} / \mathrm{h}, 40^{\circ} \mathrm{C}\end{array}$ & $\begin{array}{l}\text { Number of straight } \\
\text { pipe length in front } \\
\text { of clamp-on meter }\end{array}$ & Type & Size & Max flow $\left(\mathrm{m}^{3} / \mathrm{h}\right)$ \\
\hline 1a & 30.0 & 20800 & $43 \mathrm{D}$ & Magnetic & DN 20 & 3 \\
\hline $1 b$ & 30.0 & 20800 & $43 \mathrm{D}$ & Fluidic & DN 25 & 10 \\
\hline $1 \mathrm{c}$ & 30.0 & 20800 & $43 \mathrm{D}$ & Turbine & DN 20 & 3 \\
\hline 2 & 53.9 & 10800 & $14 \mathrm{D}$ & Fluidic & DN 50 & 48 \\
\hline 3 & 42.4 & 14100 & $18 \mathrm{D}$ & Magnetic & DN 20 & 10 \\
\hline 4 & 60.2 & 9600 & $20 \mathrm{D}$ & Magnetic & DN 50 & 36 \\
\hline
\end{tabular}


Table 2

Data for the three clamp-on meters used in the measurements

\begin{tabular}{lccc}
\hline Clamp-on meter & 'X' & 'Y' & 'Z' \\
\hline Manufacturing year & 1988 & 1994 & 1995 \\
Maximum flow velocity & $12 \mathrm{~m} / \mathrm{s}$ & $12 \mathrm{~m} / \mathrm{s}$ & $32 \mathrm{~m} / \mathrm{s}$ \\
Flow inaccuracy & & - & $< \pm 1.5 \%$ \\
$\quad$ at flow velocity $>2.0 \mathrm{~m} / \mathrm{s}$ & - & $< \pm 5 \%$ & $< \pm 0.03 \mathrm{~m} / \mathrm{s}$ \\
$\quad$ at flow velocity $<2.0 \mathrm{~m} / \mathrm{s}$ & - & $<$ & - \\
$\quad$ at flow velocity $>0.3 \mathrm{~m} / \mathrm{s}$ & $< \pm 3 \%$ & $0.05 \mathrm{~m} / \mathrm{s}$ & - \\
$\quad$ at flow velocity $<0.3 \mathrm{~m} / \mathrm{s}:$ & $< \pm 0.01 \mathrm{~m} / \mathrm{s}$ & \\
\hline
\end{tabular}
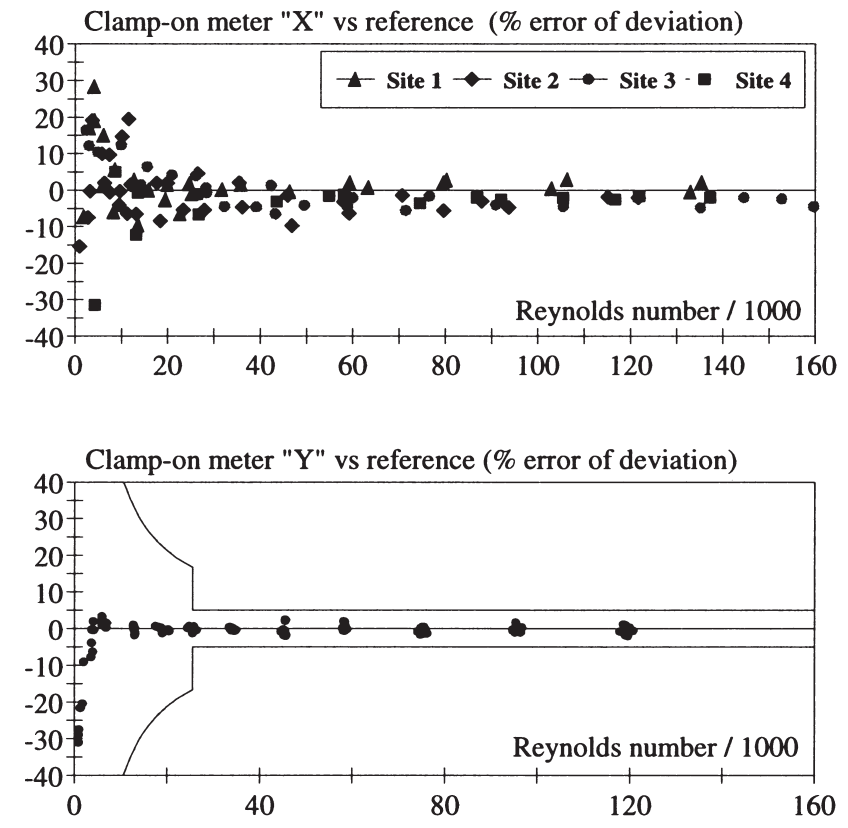

Fig. 2. Calibration results for clamp-on meters ' $\mathrm{X}$ ' and ' $\mathrm{Y}$ ' showing the deviation vs the calibration reference (points) and the specified accuracy for meter ' $\mathrm{Y}$ ' (lines). The measurements consisted of three series for each pipe. The clamp-on meter was reclamped between the series.

The calibration results for meter ' $\mathrm{X}$ ' show that when Reynolds number is above 15000 the error is $-1.8 \pm$ $6.3 \%$ assuming a Gaussian distribution and a $95 \%$ confidence interval. This interval includes the errors due to the reclamping of the meter between the calibration series. At lower flow rates the deviation can be $\pm 20 \%$ or more. This means that meter ' $\mathrm{X}$ ' does not meet the technical specifications from Table 2. Meter ' $\mathrm{Y}$ ' is more stable. Above a Reynolds number of 10000 the error is $-0.2 \pm 1.9 \%$ for a $95 \%$ confidence interval. Statistical calculations of the differences between the three calibration series, with the clamp-on meter being reclamped between the series, shows that reclamping can yield an error margin of about $1 \%$ even though the mounting was performed with the greatest care.

Since [according to the calibration results in Fig. 2] meter ' $\mathrm{Y}$ ' is sufficiently stable, it is possible to compensate the results from the measurements for the calibration results. The calibration results shows that there are three regions in which the deviation is approximately linear. Dividing the calibration data and using a linear mean square method to create three regression lines and calculating the points of intersection between these lines, we obtain three equations for the correction term,

$$
\begin{aligned}
& k=-34.25+8.37 \cdot 10^{-3} \cdot \mathrm{Re}_{\mathrm{ref}} \\
& \text { for } 0<\mathrm{Re}_{\mathrm{ref}}<4400 \\
& k=+3.79-0.32 \cdot 10^{-3} \cdot \mathrm{Re}_{\mathrm{ref}} \\
& \quad \text { for } 4400<\mathrm{Re}_{\mathrm{ref}}<12300 \\
& k=-0.11-0.02 \cdot 10^{-3} \cdot \mathrm{Re}_{\mathrm{ref}} \\
& \quad \text { for } 12300<\mathrm{Re}_{\mathrm{ref}}<125000
\end{aligned}
$$

The Reynolds numbers in Eq. (1) relates to the calibration reference $\left(\mathrm{Re}_{\mathrm{ref}}\right)$ and $k$ is obtained in \%. The correction term can in general be expressed as the following:

$k=\alpha+\beta \cdot \operatorname{Re}_{r e f}$

During the field measurements, the Reynolds numbers are calculated with meter ' $\mathrm{Y}$ ' as reference $\left(\operatorname{Re}_{\mathrm{Y}}\right)$. From the calibration the deviations was stated as the following:

$k=100 \cdot\left(\operatorname{Re}_{\mathrm{Y}}-\operatorname{Re}_{\mathrm{ref}}\right) / \operatorname{Re}_{\mathrm{ref}}$.

Using Eqs (2) and (3) and calculating $k$, we get:

$k=(\alpha / 2-50)+\sqrt{(\alpha / 2-50)^{2}+100 \cdot\left(\alpha+\beta \cdot \operatorname{Re}_{\mathrm{Y}}\right)}$.

Since $\operatorname{Re}_{\mathrm{Y}}$ is a value obtained from the field measurements, the correction term can be calculated. Furthermore $\mathrm{Re}_{\text {ref }}$ can be calculated. The data points from the measurements in the subscriber stations are calculated as the deviation between the clamp-on meter and the billing flow meter. This deviation, called $f$ and obtained in $\%$, is stated as follows:

$f=100 \cdot\left(\operatorname{Re}_{\mathrm{Y}}-\mathrm{Re}_{\mathrm{BM}}\right) / \mathrm{Re}_{\mathrm{BM}}$ 
where $\mathrm{Re}_{\mathrm{BM}}$ is the Reynolds number for the billing flow meter. Now it is possible to find the deviation between the corrected data from the clamp-on meter ' $Y$ ' and the billing flow meter, $e$, obtained in \%:

$$
\begin{aligned}
e & =\frac{\operatorname{Re}_{r e f}-\operatorname{Re}_{B M}}{\operatorname{Re}_{B M}} \cdot 100=\left(\frac{\operatorname{Re}_{r e f}}{\operatorname{Re}_{Y}} \cdot \frac{\mathrm{Re}_{Y}}{\operatorname{Re}_{B M}}-1\right) . \\
100 & =\frac{f-k}{1+0.01 \cdot k} .
\end{aligned}
$$

\section{Results}

For method (A) the following data was obtained: Measurements were made in two sites with two clampon meters and the results are presented in Table 3. The data are obtained from three independent measurement occasions. Clamp-on meter ' $\mathrm{Y}$ ' shows a large mean deviation to the billing flow meter at site 1 and cannot measure at site 2 due to very low signal quality when placed on the ordinary pipes. To be able to compare the data from ordinary pipes, reference measurements were made on the calibrated pipes used in part (B). The most interesting parameter is the scatter of the deviation between the clamp-on meter and the billing meter. Also seen in Table 3, the confidence interval is much larger for the measurements made on the ordinary pipes.

Meter ' $\mathrm{Z}$ ' has a large mean deviation to the billing flow meter at site 1 and also a large confidence interval both on ordinary and calibrated pipes. This could be explained by the relatively low flow rates in this site. Clamp-on meter ' $\mathrm{Z}$ ' does not work very well below a Reynolds number of 10000 as shown in Fig. 3, which in this case correspond to $0.08 \mathrm{~m} / \mathrm{s}$. It should be mentioned that meter ' $\mathrm{Z}$ ' meets the manufacturers specification, but it is dimensioned for larger flow rates compared to those present in this site. At site 2, the results are acceptable for meter ' $Z$ '.

From these results it is concluded that normally the deviation and scatter of data are too high to be useful in

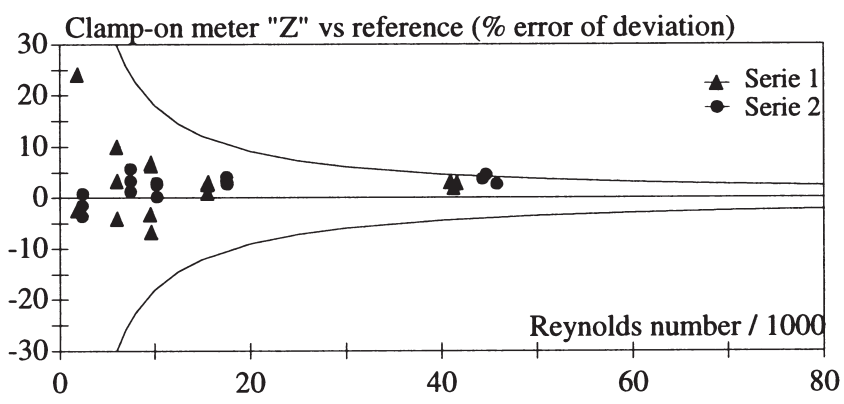

Fig. 3. Calibration results for clamp-on meter ' $\mathrm{Z}$ ' showing the deviation vs the calibration reference for Reynolds number up to 50000 (points) and the specified accuracy for meter ' $Z$ ' (lines). The measurements consists of two series. The clamp-on meter was reclamped between the series.

comparing the billing flow meter and the clamp-on meters when using the ordinary pipes in the metering sites.

For method (B) the following data was obtained: Measurements were made on four sites with two clampon meters. Most data are summarized in Figs 4-8. The data point represents the deviation between the clampon meter and the billing flow meter using the billing meter as reference. The figures also show the manufacturers' specified error limits for respective clamp-on meter.

At site 1, three billing flow meters where mounted in series. Two of these meters failed during the tests. One had an error in the signal converter and pulse output (No. 1a in Table 2). Thus only two measurements were obtained [Fig. 4(a,b)]. The second meter's (No. 1b) showed large scatter in collected readings [Fig. 4(c,d)]. In this case the results become clearer when shown chronologically. In Fig. 5 we see that the clamp-on meter readings are following each other although the deviations to the billing flow meter vary between $\pm 20 \%$. It is therefore probable that the billing flow meter is in error. The third meter (No. 1c) has a deviation when compared with the clamp-on meters between - 10 and $0 \%$ in all cases except one. The results for meter ' $\mathrm{X}$ ' vs meter 1c may be due to error of meter ' $X$ ', cf. Fig. 2(a).

Table 3

Results from measurements on ordinary pipes

Reynolds-number/1000 min/max

\begin{tabular}{lccc}
\hline & Reynolds-number/1000 min/max & $\begin{array}{c}\text { Ordinary pipes (mean deviation } \pm \\
95 \% \text { confidence intervals) } \\
\text { (ref.:Billing flow meter) }\end{array}$ & $\begin{array}{c}\text { Calibrated pipes (mean deviation } \pm \\
95 \% \text { confidence intervals) } \\
\text { (ref.:Billing flow meter) }\end{array}$ \\
\hline Meter Y: & $8 / 12$ & & $-2.9 \pm 1.4 \%$ \\
Site 1 & $55 / 70$ & $+12.6 \pm 6.5 \%$ & $-1.4 \pm 1.8 \%$ \\
Site 2 & $8 / 12$ & Very low signal & $+10.5 \pm 5.8 \%$ \\
Meter Z: & $55 / 70$ & $+12.7 \pm 9.3 \%$ & $-2.0 \pm 5.8 \%$ \\
Site 1 & & $+1.1 \pm 3.4 \%$ & \\
Site 2 & &
\end{tabular}




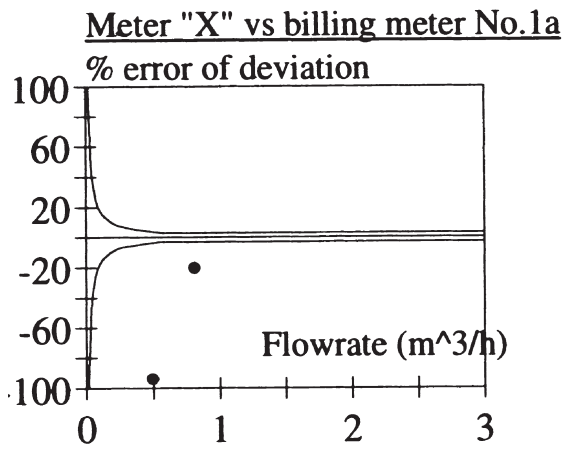

(a)

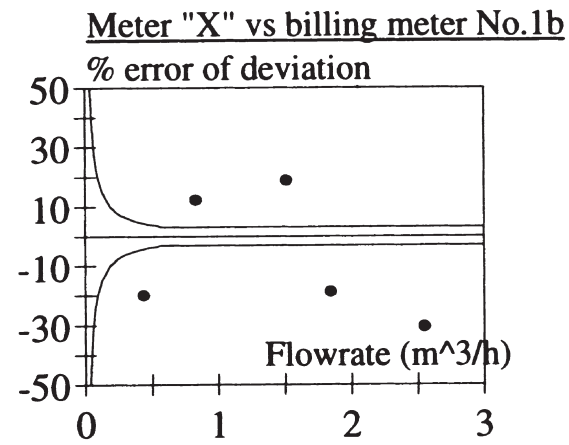

(c)

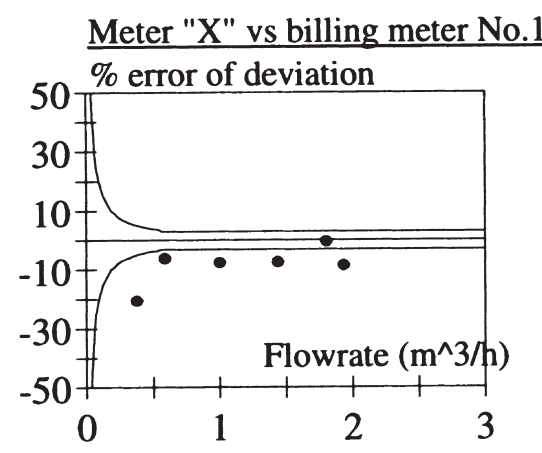

(e)

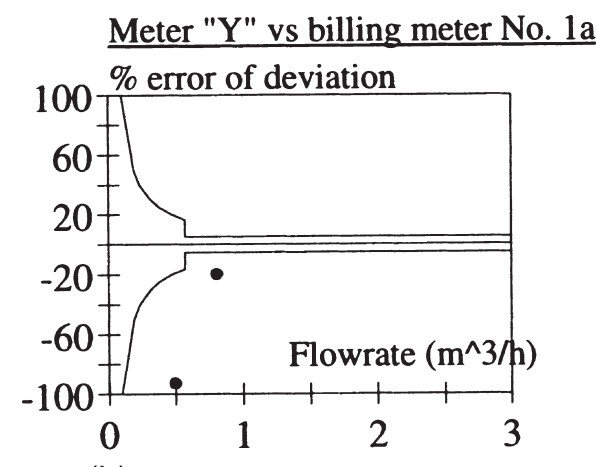

(b)

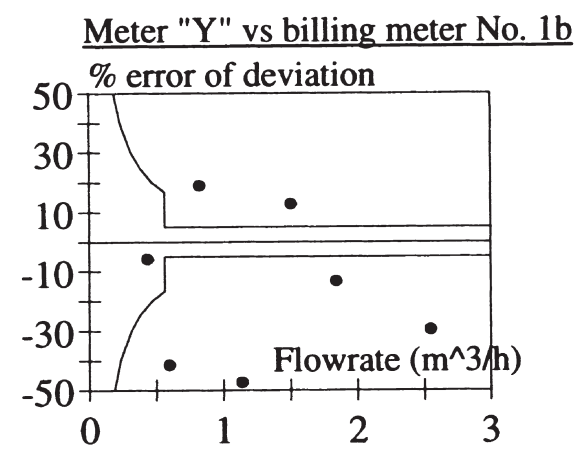

(d)

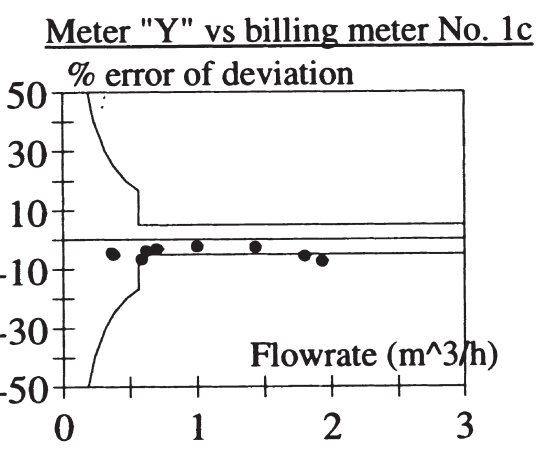

(f)

Fig. 4. Summary of data from metering site 1. The deviation of clamp-on meter ' $\mathrm{X}$ ' vs the billing meter (points) and the specified accuracy for meter ' $\mathrm{X}$ ' (lines) are shown in (a), (c) and (e). Corresponding results for clamp-on meter ' $\mathrm{Y}$ ' are shown in (b), (d) and (f).

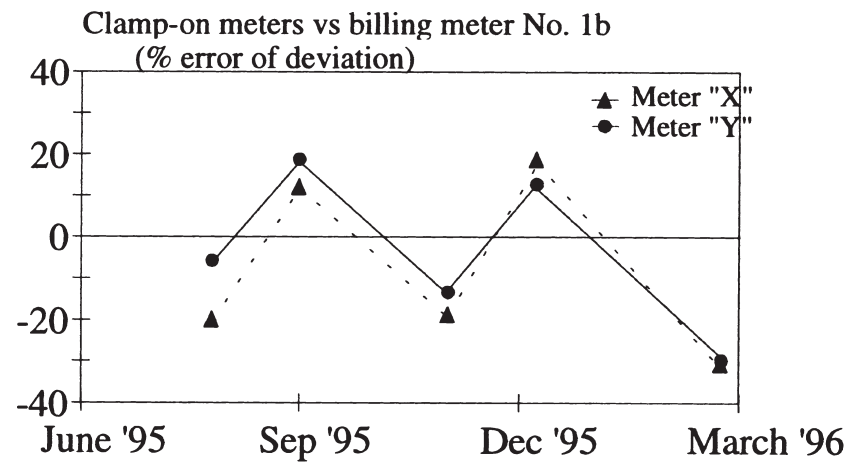

Fig. 5. Summary of measured data from metering site 1 for billing meter $1 \mathrm{~b}$, shown in chronological order. Billing meter probably in error, since the clamp-on meter readings are following each other.
At site 2 [Fig. 6(a,b)] the results are similar to site $1 \mathrm{c}$ but the flow rates are higher and the scattering between the billing flow meter and the clamp-on meters are clearly smaller, between -5 to $0 \%$. At site 3 [Fig. $7(\mathrm{a}, \mathrm{b})]$ we see that the flow rates are very low and the scatter for clamp-on meter ' $X$ ' compared with the billing flow meter is large. This is probably due to large precision errors for meter ' $\mathrm{X}$ ' at these flow rates, cf. Fig. 2. According to calibration data, clamp-on meter ' $\mathrm{Y}$ ' has a large bias error and a reasonable precision at these low flow rates. Thus, it would be possible to linearise meter ' $\mathrm{Y}$ ' to obtain a larger test range. At site 4 [Fig. 8(a,b)] the flow rates are also low. Clamp-on meter ' $\mathrm{X}$ ' has large scatter compared with the billing flow meter, but the scatter on clamp-on meter ' $\mathrm{Y}$ ' is only between -5 and $0 \%$ (except for the lowest flow rates). 

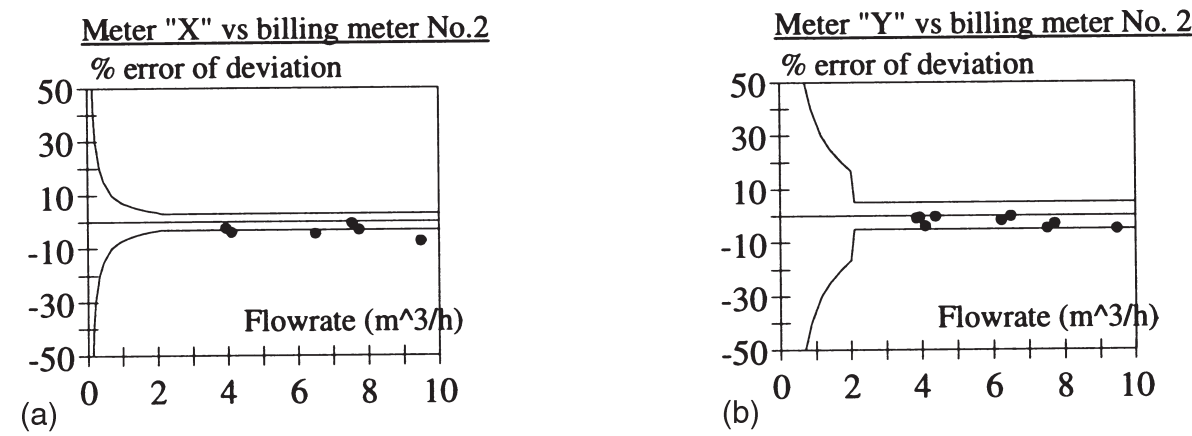

Fig. 6. Summary of data from metering site 2. The deviation of clamp-on meter ' $X$ ' vs the billing meter (points) and the specified accuracy for meter ' $\mathrm{X}$ ' (lines) are shown in (a). Corresponding results for clamp-on meter ' $\mathrm{Y}$ ' are shown in (b).

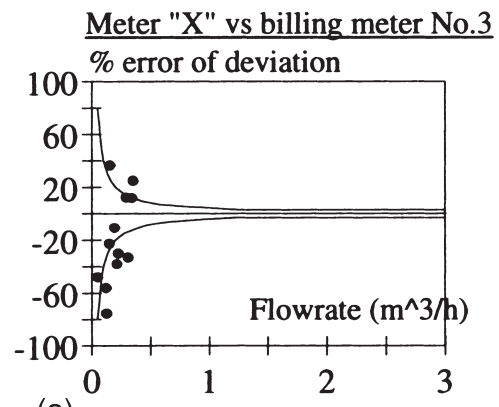

(a)

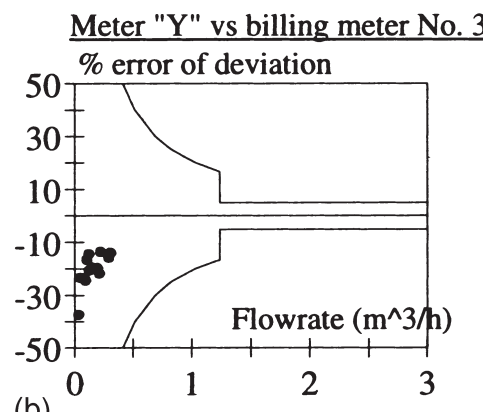

(b)

Fig. 7. Summary of data from metering site 3. The deviation of clamp-on meter ' $X$ ' vs the billing meter (points) and the specified accuracy for meter ' $\mathrm{X}$ ' (lines) are shown in (a). Corresponding results for clamp-on meter ' $\mathrm{Y}$ ' are shown in (b).

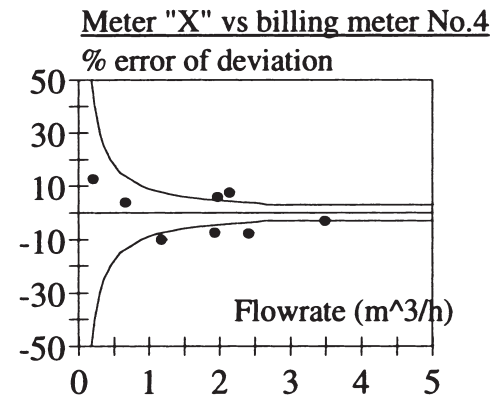

(a)

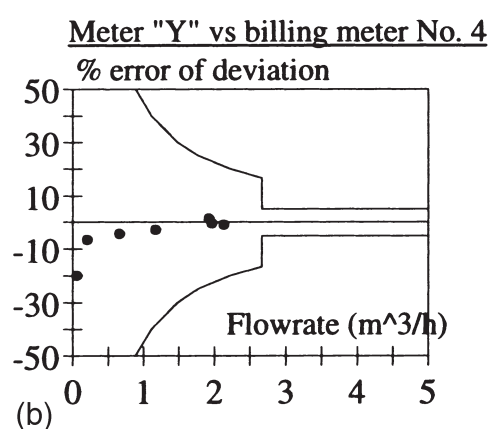

(b)

Fig. 8. Summary of data from metering site 4. The deviation of clamp-on meter ' $\mathrm{X}$ ' vs the billing meter (points) and the specified accuracy for meter ' $\mathrm{X}$ ' (lines) are shown in (a). Corresponding results for clamp-on meter ' $\mathrm{Y}$ ' are shown in (b).

For method (C) the following data were obtained after calibration correction of measured data from clamp-on meter ' $\mathrm{Y}$ '. The correction data from billing flow meters $1 \mathrm{a}$ and $1 \mathrm{~b}$ are not shown since they revealed to be faulty in part (B). The results from site 1c and 2 [Fig. 9(a) and 9(b)] are almost equal to the results obtained in part (B) since the flow rates are high and the corrections in these high flow rates only influence the results slightly.

At site 3 [Fig. 9(c)], the deviation between the clampon meter and the billing flow meter is displaced from approximately $-20 \pm 10 \%$ to $-5 \pm 10 \%$ after the calibration correction. This shows that the billing flow meter is working with acceptable accuracy despite that the flow rates only correspond to approximately $1-3 \%$ of the meters maximum design flow rate. This is near the minimum design flow rate, which corresponds to $1 \%$ of maximum flow rate. At site 4 [Fig. 9(d)], the deviations at low flow rates of approximately $-20 \%$ has been compensated to approximately $\pm 10 \%$.

The slope of the regression line for a Reynolds number below 4400 is very steep [cf. Eq. (1)]. Therefore, a small deviation from the regression line gives a large resulting deviation between the clamp-on meter and the billing flow meter. Further, when calculating a 95\%-confidence interval for the regression line in this region, the 


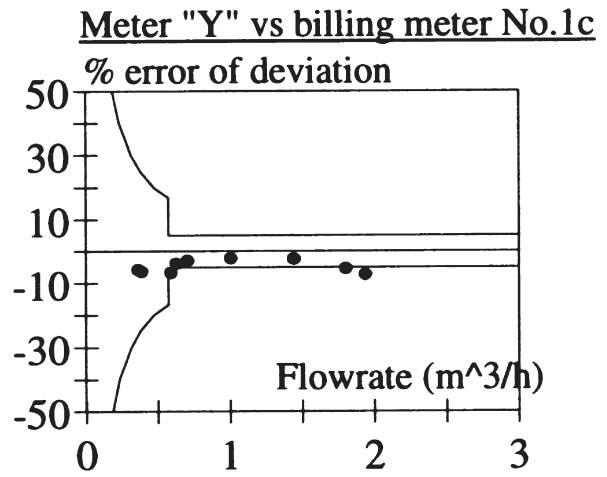

(a)

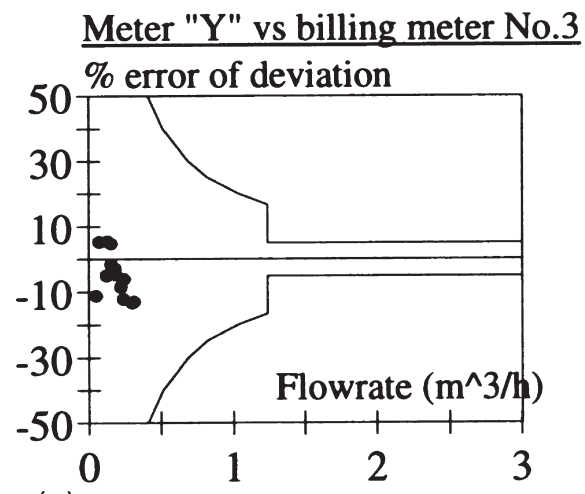

(c)

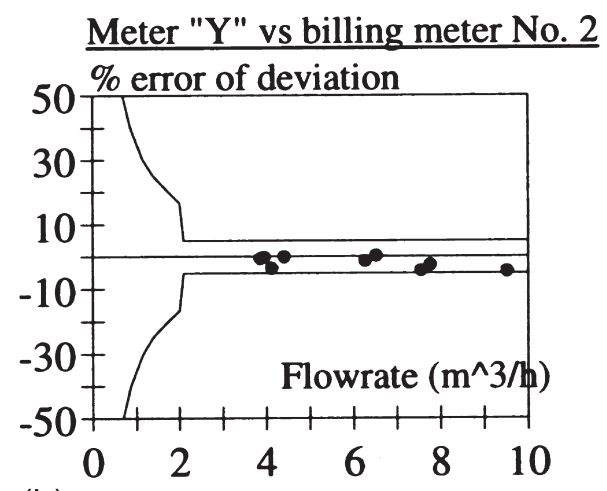

(b)

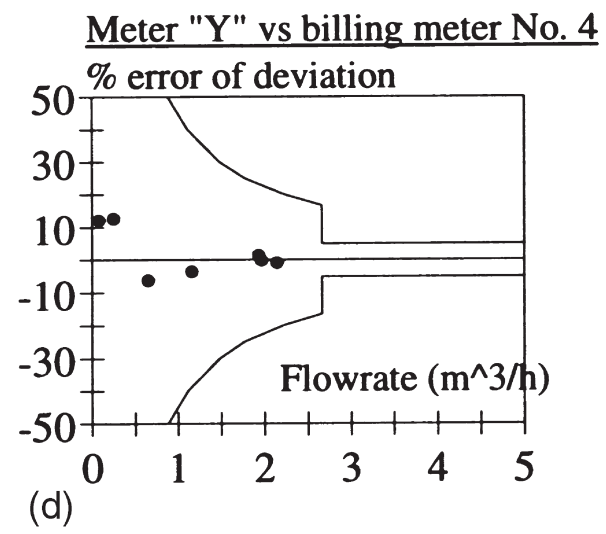

Fig. 9. Summary of data from metering site 1c (a), 2 (b), 3 (c) and 4 (d). The deviation of clamp-on meter ' $\mathrm{Y}$ ' after calibration correction vs the billing flow meters (points) and the specified accuracy for meter ' $\mathrm{Y}$ ' (lines).

results is $\pm 7.5 \%$. Nevertheless, the results from the last two sites shows that the correction method results in an improved accuracy for the deviation determination between the clamp-on meter and the billing flow meter in an extended range, mainly at low flow rates and deviations larger than around $\pm 10 \%$ can be detected at these extended lower flow rates.

\section{Discussion}

When the clamp-on meters were used directly on the ordinary pipes, the data scatter was in general large. There were also problems with low signal levels and large precision errors from meter ' $Y$ '. Meter ' $\mathrm{Z}$ ' showed good precision error in one metering site, but a large precision error was noticed in the other. Another problem was the determination of pipe data. It was difficult to know the exact pipe wall thickness and whether any internal liner coating was present.

When using the well defined pipes mounted in series with the billing meter it is clearly shown that faulty billing meter operation can be detected. When the flow rates are above a Reynolds number of approximately 10000 for meter ' $\mathrm{Y}$ ' and approximately 30000 for meter ' $\mathrm{X}$ ', the results are good and comparison measure- ments between the clamp-on meters and the billing flow meters can be made to detect deviations $> \pm 5 \%$ of the billing flow meter. At lower flow rates, the data scatter can be large and the method is less reliable. Below a Reynolds number of approximately 5000, the data scatter is large and it is not recommended to use clamp-on meters for comparison measurements in this low flow region. Since some of the billing flow meters were operating in this region, this would suggest that the sizing of the flow meters and pipes in district heating subscriber stations may be questionable.

When applying calibration data to the clamp-on meter, an extended testing range is obtained, thus enabling in situ tests at low flow rates. For a Reynolds number below approximately 5000, the steep slope of the regression line makes the results sensitive even to minor deviations between the clamp-on meter and the billing flow meter. However, our data indicates that it is possible to detect deviations $> \pm 10 \%$ of the billing flow meters in this low flow region. Finally, the work also indicates that not all brands of clamp-on meters are useful for in situ testing. 


\section{References}

[1] Spitzer DW. Flow measurement. Practical Guides for Measurement and Control. Instrument Society of America, 1991.

[2] Turtiainen H. FLOWCER - a flowmeter based on radiotracer techniques. Technical Research Centre of Finland. Report VTTTIED-638, 1986 (in Finnish).

[3] Viitanen P. Process flow measurement based on tracer techniques. Methods and their accuracies. Technical Research Centre of Finland. Report VTT-TIED-823, 1988 (in Finnish).

[4] Kuoppamäki R. On site calibration of district heating flow meters. 23th Unichal Congress, Berlin, 17-19 June, 1987.

[5] Sevel T. The use of tracer technics for in situ control and calibration of flowmeters in waste water, district heating systems and gasflare system. The 16th Nordic Conference Measuring Technics and Calibration, Helsingör, 1994 (in Danish).

[6] Benkert J et al. Flow measurement systems with the aid of correlation analysis. In Forschritt.-Ber. VDI Z., Ser. 7, No. 50. VDI, 1979 (in German).
[7] Morris AS. Principles of Measurement and Instrumentation. Englewood Cliffs, NJ: Prentice-Hall, 1993.

[8] Haberl JS et al. Calibration of flowmeters for use in HVAC systems monitoring. Texas A\&M University, College Station, TX. ASME, New York, 1992: 1277-83.

[9] Cairney WD. Typical flow measurement problems and their solution in the electricity supply industry. Flow Measurement and Instrumentation 1991;2:Oct.

[10] Brumer RF. Theoretical and experimental assessment of uncertainties in non-intrusive, ultrasonic flow measurement. National Bureau of Standards, Special Publication 484. Proc. of the Symposium on Flow in Open Channels and Closed Conduits held at NBS, Gaithersburg, 1977: 277-91.

[11] Sanderson ML, Torley B. Error assessment for an intelligent clamp-on transit time ultrasonic flowmeter. International Conference on Flow Measurement in the Mid 80's. East Kilbridge, Glasgow: National Engineering Laboratory, 1986.

[12] DIN 1626: Welded Steel Pipes. 1965 (in German).

[13] Lynnworth LC. Ultrasonic flowmeters. In Physical Acoustic, Principles and Methods, Vol. XIV. New York: Academic Press, 1979. 